\title{
Community mobilization to strengthen support for appropriate and timely use of antenatal and postnatal care: A review of reviews
}

\author{
Sara Dada ${ }^{1,2}$, Özge Tunçalp ${ }^{3}$, \\ Anayda Portela ${ }^{4}$, María \\ Barreix ${ }^{3}$, Brynne Gilmore ${ }^{1,2}$ \\ ${ }^{1}$ UCD Centre for Interdisciplinary \\ Research, Education and Innovation \\ in Health Systems, School of \\ Nursing, Midwifery and Health \\ Systems, University College Dublin, \\ Dublin, Ireland \\ ${ }^{2}$ School of Nursing, Midwifery and \\ Health Systems, University College \\ Dublin, Dublin, Ireland \\ 3UNDP/UNFPA/UNICEF/WHO/ \\ World Bank Special Programme \\ of Research, Development and \\ Research Training in Human \\ Reproduction, Department of \\ Sexual and Reproductive Health \\ and Research, World Health \\ Organization, Geneva, Switzerland \\ ${ }^{4}$ Department of Maternal, Newborn, \\ Child and Adolescent Health and \\ Ageing, World Health Organization, \\ Geneva, Switzerland
}

Background Antenatal care (ANC) and postnatal care (PNC) are critical opportunities for women, babies and parents/families to receive quality care and support from health services. Community-based interventions may improve the accessibility, availability, and acceptance of this vital care. For example, community mobilization strategies have been used to involve and collaborate with women, families and communities to improve maternal and newborn health.

Objective To synthesize existing reviews of evidence on community mobilization strategies that strengthen support for appropriate and timely use of ANC and PNC.

Methods Six databases (MEDLINE, Embase, CINAHL, PsychINFO, Cochrane Library, PROSPERO) were searched for published reviews that describe community mobilization related strategies for ANC and/or PNC. Reviews were eligible for inclusion if they described any initiatives or strategies targeting the promotion of ANC and/or PNC uptake that included an element of community mobilization in a low- or middle-income country (LMIC), published after 2000. Included reviews were critically appraised according to the Joanna Briggs Institute (JBI) Checklist for Systematic Reviews and Evidence Syntheses. This review of reviews was conducted following JBI guidelines for undertaking and reporting umbrella reviews.

Results In total 23 papers, representing 22 reviews were included. While all 22 reviews contained some description of community mobilization and ANC/PNC, 13 presented more in-depth details on the community mobilization processes and relevant outcomes. Seventeen reviews focused on ANC, four considered both ANC and PNC, and only one focused on PNC. Overall, 16 reviews reported at least one positive association between community mobilization activities and ANC/PNC uptake, while five reviews presented primary studies with no statistically significant change in ANC uptake and one included a primary study with a decrease in use of antenatal facilities. The community mobilization activities described by the reviews ranged from informative, passive communication to more active, participatory approaches that included engaging individuals or consulting local leaders and community members to develop priorities and action plans.

Conclusions While there is considerable momentum around incorporating community mobilization activities in maternal and newborn health programs, such as improving community support for the uptake of ANC and PNC, there is limited evidence on the processes used. Furthermore, the spectrum of terminology and variation in definitions should be harmonized to guide the implementation and

evaluation efforts.

\section{Correspondence to:}

Sara Dada

University College Dublin

Belfield

Dublin 4

Ireland

sara.dada@ucdconnect.ie 
Antenatal care (ANC) and postnatal care (PNC) are critical opportunities for women, babies, parents/caregivers and families to receive quality care. A global study on ANC found significant interregional and intercountry inequalities in ANC service utilization, especially in Asia and Africa [1]. In 2016, the World Health Organization (WHO) released updated recommendations for routine ANC within the continuum of care to improve maternal and newborn health [2]. The WHO recommendations for PNC, published in 2013, are currently being updated [3,4]. With global priorities to improve the availability, accessibility and acceptability of this care, a range of studies have investigated the factors that affect the implementation of these guidelines and the utilization of both ANC and PNC services [4-6].

ANC and PNC share several common factors that may affect their uptake and utilization, including providers' skills, the relationship between health workers and women, local infrastructure such as distance and transportation to facilities, as well as the influence of women and families' knowledge, attitudes, beliefs and culture norms regarding care [7-12]. As such, the perceptions, support, and involvement of the partner, family and community members are influential [9]. Community mobilization techniques have been used to both support health promotion and educational programming ${ }^{2}$ as well as increase acceptability and accessibility to the interventions [13].

While the definition of community mobilization varies in the literature, it can largely be described as involving community members in activities to increase support and actions for an intended cause $[14,15]$. There is a spectrum of activities and approaches to mobilize communities [16]. WHO guidelines for maternal and newborn health $(\mathrm{MNH})$ also describe community-based interventions to improve communication and support and different community mobilization strategies including participatory learning and action (PLA) cycles $[6,17,18]$. Multiples studies and reviews have been conducted on community mobilization or participation interventions to promote maternal and newborn health and inform international guidelines [6,15,17-19]. These largely center around the effectiveness of such approaches and their influence on outcomes of interest, such as increasing ANC and/or PNC uptake and some report on maternal and newborn morbidity and mortality. Previous systematic reviews on community mobilization for maternal and newborn health have described initiatives such as PLA and women's groups, as an avenue to provide emotional, social, and psychological support and a cost-effective strategy to improve maternal and neonatal mortality in low-resource settings [20-23]. A larger body of work describes community-based initiatives more broadly, including a range of community mobilization activities [12,22-26].

However, there is also a need to consider the full spectrum of community mobilization activities and implementation processes, and how they improve community support for ANC/PNC. Specifically, the purpose of this review of reviews is therefore to synthesize the existing evidence on what community mobilization strategies are effective in increasing family and community support for appropriate and timely use of ANC and PNC in LMICs. Within these community mobilization strategies, the review also seeks to understand what strategies are used to strengthen family and community support for use of ANC in the first trimester of pregnancy. The findings of this review of reviews are then applied to the 2019 logic model pathway for uptake of ANC services described by Downe et al, which underpins the WHO recommendations on ANC [27].

\section{METHODS}

A systematic review of reviews was conducted in order to gather existing evidence on community mobilization strategies that strengthen support for appropriate and timely use of ANC/PNC, including use of ANC in the first trimester of pregnancy. This approach summarizes the findings of published reviews to synthesize existing evidence in an overview that can inform future guidelines, programmes, and policy [28-30]. As there are already existing systematic reviews on community mobilization within reproductive, maternal, newborn and child health (RMNCH), this methodology was chosen to provide high level evidence on such strategies for ANC/PNC and to reveal where findings are consistent [31,32]. Table 1 exhibits the operational definitions of the terms used in this review of reviews.

\section{Eligibility criteria}

Studies were eligible for inclusion if they described any interventions, initiatives or strategies targeting the promotion of ANC and/or PNC uptake that included an element of community mobilization in a low-and middle-income country (LMIC), as defined by the World Bank Classification at time of study. Eligible reviews of published literature included, but were not limited to, literature reviews, narrative reviews, realist reviews, 
Table 1. Operational definitions

\begin{tabular}{|c|c|}
\hline TERM & DEFINITION \\
\hline $\begin{array}{l}\text { Community } \\
\text { Mobilization }\end{array}$ & $\begin{array}{l}\text { Community mobilization interventions "encourage community individuals, groups (including in schools), or organizations to plan, } \\
\text { carry out, and evaluate activities on a participatory and sustained basis to improve their health and other needs" [15]. For example, } \\
\text { community mobilization includes PLA cycles, community dialogues, and community advocacy activities [15,18]. }\end{array}$ \\
\hline $\begin{array}{l}\text { Antenatal Care } \\
\text { (ANC) }\end{array}$ & $\begin{array}{l}\text { "The health care women get while they are pregnant," [27] includes health screenings, information sharing, counselling, vaccination } \\
\text { administration, preventive and curative treatments, and more. }\end{array}$ \\
\hline Early ANC & According to WHO guidelines, early ANC is within the first trimester, or often gestational age of $\leq 12$ weeks [6]. \\
\hline $\begin{array}{l}\text { Appropriate \& } \\
\text { timely use of care }\end{array}$ & $\begin{array}{l}\text { Appropriate and timely use of ANC and PNC is based on adhering to country and/or WHO guidelines on the number and timing of } \\
\text { contacts. }\end{array}$ \\
\hline $\begin{array}{l}\text { Postnatal Care } \\
(\mathrm{PNC})\end{array}$ & $\begin{array}{l}\text { The care received by the woman and the newborn after childbirth [3]. The exact definition of the postnatal period can vary, but is } \\
\text { often considered the first six weeks after birth [4]. }\end{array}$ \\
\hline
\end{tabular}

PLA - participatory learning and action, ANC - antenatal care, PNC - postnatal care

systematic reviews, scoping reviews, and qualitative evidence syntheses. Only studies published on or after 2000 were included. This year was chosen as a cut-off point in order to capture more relevant research, aligning with the Millennium Development Goals and increased attention on ANC/PNC for maternal, newborn and child health and with the growing focus on community-based interventions such as community mobilization. Table 2 details the inclusion and exclusion criteria.

Table 2. Inclusion/exclusion criteria

\begin{tabular}{lll} 
TOPIC & INCLUSION CRITERIA & EXCLUSION CRITERIA \\
Population & $\begin{array}{l}\text { Pregnant and postpartum women, companions, birth partners, fathers/caregivers, } \\
\text { family members, decision-makers, local authorities/community leaders, } \\
\text { community health workers and service providers }\end{array}$ & \\
\hline $\begin{array}{l}\text { Exposure/ } \\
\text { Intervention }\end{array}$ & $\begin{array}{l}\text { Initiatives/strategies/interventions targeting promotion of ANC and/or PNC } \\
\text { uptake that include an element of community mobilization }\end{array}$ & $\begin{array}{l}\text { No identifiable community mobilization component; use } \\
\text { of community health workers or other health providers } \\
\text { only to deliver services with no identifiable community } \\
\text { mobilization component aimed at increasing ANC/PNC. }\end{array}$ \\
\hline Outcome & Promotion of ANC/PNC care-seeking behavior; promotion of early ANC & Not focused on promoting ANC/PNC \\
\hline Setting & $\begin{array}{l}\text { Focus on LMIC, as defined by World Bank Classification at time of study. } \\
\text { Reviews that include studies in high- income countries and LMICs were } \\
\text { considered if evidence from LMICs could be extrapolated. }\end{array}$ & Reviews with no LMICs represented \\
\hline Time & Published on or after 2000 & Published before 2000 \\
\hline Article type & $\begin{array}{l}\text { Reviews of published literature including literature reviews, narrative reviews, } \\
\text { realist reviews, systematic reviews, scoping reviews, qualitative syntheses, etc. }\end{array}$ & $\begin{array}{l}\text { Primary, empirical studies; commentaries; abstracts; grey } \\
\text { literature }\end{array}$ \\
\hline Language & All languages included, but search conducted mainly in English. &
\end{tabular}

ANC - antenatal care, PNC - postnatal care, LMIC - low and middle-income country

\section{Search strategy}

The search strategy was designed around three main concepts: community mobilization, ANC/PNC, and reviews (Appendix S1 in the Online Supplementary Document). The search was run across six databases (MEDLINE, Embase, CINAHL, PsychINFO, Cochrane Library, PROSPERO) and snowballing techniques, including examining the bibliographies of included reviews as well as a relevant publication mapping social, behavioral, and community-engagement (SBCE) interventions [15] and key websites (Google Scholar, MASCOT) were conducted. No language restrictions were applied, but the search strategy was run in English.

\section{Study selection and management}

All returns from the database search were imported into Covidence, an online information management system. After managing for duplicates, two reviewers (SD, BG) independently screened the resulting studies' titles and abstracts. After discussing any conflicts, the reviewers analyzed full texts to determine final inclusion data set, again discussing any conflicts. A third reviewer (AGP) reviewed 20\% of the included and excluded articles at full-text stage. 


\section{Data extraction}

One reviewer (SD) extracted data from all included studies into an Excel sheet using a pre-developed data extraction tool. Review characteristics and findings relevant to community mobilization and ANC/PNC uptake were considered. Extracted data included: number of studies and geographic range, participants, specific community mobilization strategies used, barriers and facilitators to activity implementation, outcomes reported in the review, recommendations by the review authors, etc. A second reviewer (BG) independently extracted data on approximately $20 \%$ of included reviews to compare for inter-rater reliability and resolve any potential discrepancies and also examined all other extracted data for consistency. Data was extracted as it was presented in the published reviews. Reviewers did not extract from the primary sources that were referenced. This led to varying levels of detail in the major findings of reviews as some reported specific outcomes of primary studies while others did not.

\section{Critical appraisal}

Two reviewers (SD, BG) assessed the quality of the included reviews using the Joanna Briggs Institute (JBI) Checklist for Systematic Reviews and Research Syntheses [30,33]. This tool was used due to the range of review methodologies and formats included.

\section{Data synthesis}

Findings from the data extraction were synthesized to answer the research questions previously presented. This was done by collecting the overall conclusions on community mobilization and reported outcomes for ANC and/or PNC utilization, listing the range of mentioned community mobilization strategies and activities used within $\mathrm{MNH}$ programmes, and grouping reviews that included community mobilization that impacted on early ANC uptake. In addition to presenting evidence from the included reviews, this review used findings from a recent qualitative evidence synthesis on routine ANC uptake to contextualize some of the practical implications for community mobilization [27]. Downe et al. identified perceptions and experiences of pregnant women and health care providers related to the initial and continued use of ANC and presented these findings following the theory of planned behavior framework [27,34].

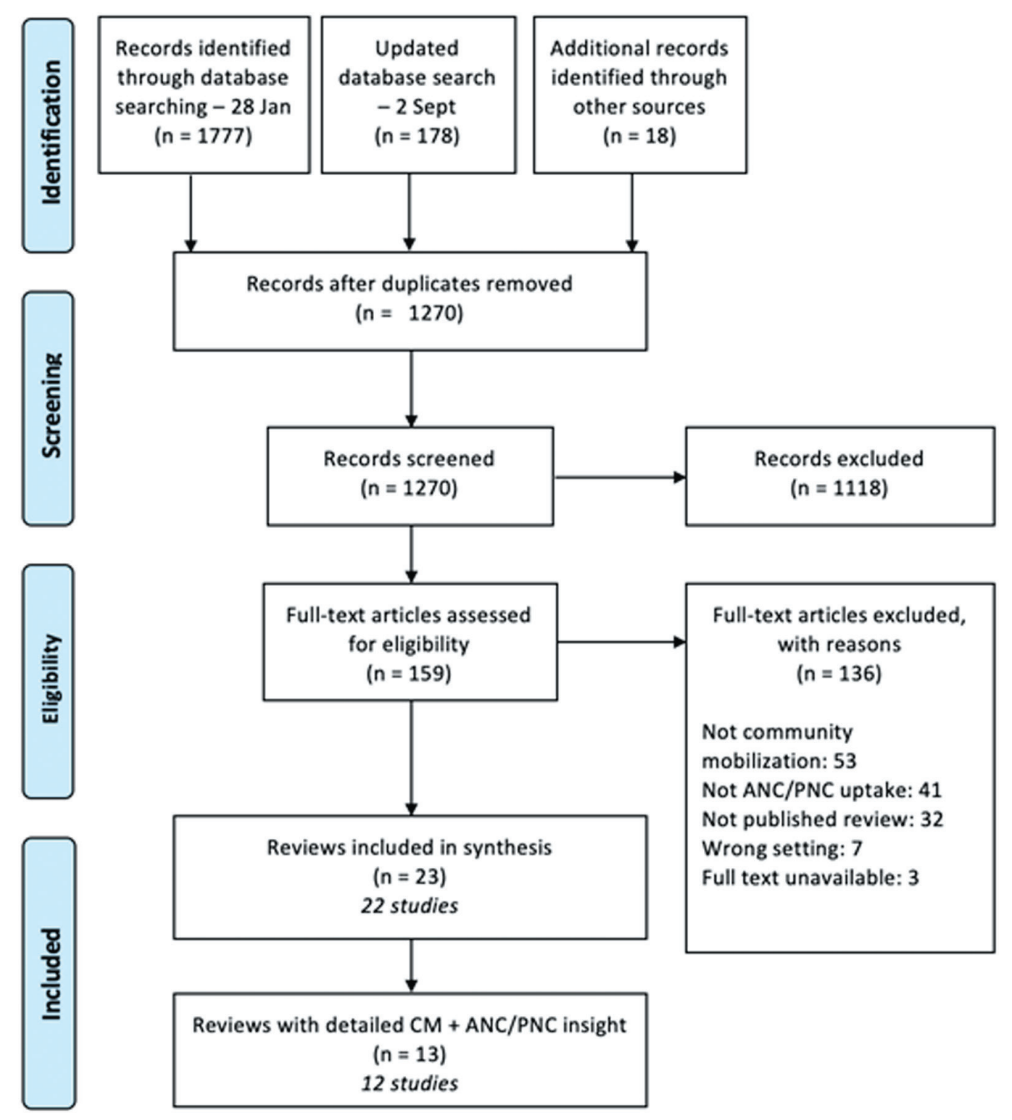

Figure 1. PRISMA screening diagram [35].

\section{RESULTS}

Searching occurred between 28 January and 15 February 2021. An updated database search was conducted on 2 September 2021. As highlighted in Figure 1, a total of 1955 records were identified during database searching. After removal of duplicates, 1270 articles were screened at title and abstract stage, with 153 full texts screened. An additional 18 resources were reviewed after snowballing, with 6 screened at full-text stage. In total 23 articles [20,21,23,36-55], representing 21 reviews were included, as two of these articles $[47,48]$ were from the same multi-part review and are henceforth referred to as one review.

The JBI Critical Appraisal tool was applied to all included studies and the assessments are available in Appendix S2 in the Online Supplementary Document. No reviews were excluded based on quality, however the challenges reviews faced in terms of quality centered around appropriate and validated appraisal processes as well as clear strategies and sources. Additionally, it is important to note that while all reviews presented included some description of community mobilization and ANC/PNC, 12 articles presented more in-depth details on the community mobilization processes 
and outcomes relevant to this review of reviews $[21,23,39,41-44,47-49,51,53]$. This means that the review itself explicitly defined or described how community mobilization was implemented as well as the potential impact those activities had on ANC/PNC uptake. For the remaining 10 reviews, there was limited detail to sufficiently extract data on what community mobilization activity was implemented, though they did report on ANC/PNC uptake.

\section{Review characteristics}

The 22 reviews ranged in size and scope. Table 3 highlights some key characteristics and details the interventions and findings of interest to this review. This range in reviews was intentional as the search strategy was designed to include reviews of different focuses that contained any element of community mobilization and ANC/PNC uptake. The reviews utilized varying methodologies and included: systematic reviews $(n=11)$, meta-analyses $(n=3)$, evidence reviews $(n=3)$, narrative review $(n=1)$, integrative review $(n=1)$, scoping review $(n=1)$, and general reviews/syntheses $(n=2)$. Reviews focused on LMIC settings globally $(n=12)[21,23,37$ $40,43,44,47-50,54]$, sub-Saharan Africa $(n=4)[20,36,52,53]$, and South Asia $(n=3)[46,51,55]$. Three reviews had no geographic limitations and typically specified findings from high-, middle-, and low-income settings $[41,42,45]$. In terms of the Sustainable Development Goals (SDG) regions, Central and Southern Asia $(n=18)$ was the most represented region in the reviews, followed by Sub-Saharan Africa $(n=17)$, Latin America and the Caribbean $(n=8)$ and Eastern and South-Eastern Asia $(n=8)$, Europe and North America $(n=7)$, Northern Africa and Western Asia ( $n=3)$, and then Oceania $(n=2)$. Appendix S3 in the Online Supplementary Document displays the breakdown in representation across the SDG regions. While the earliest review included was published in 2010, there has been a steady increase in publications on this subject over the last decade. Sixteen of the included reviews were published in or after 2015.

Most reviews focused broadly on RMNCH $[21,23,36,38-40,42-44,46-51,53,54]$. One review specifically focused on ANC [45], one on PNC [37], and one on both ANC and PNC [41]. The last two included reviews focused on maternal health for women with HIV or prevention of mother-to-child-transmission (PMTCT) of HIV [20,52]. Eleven of the reviews aimed to synthesize evidence on community mobilization and/or community-based interventions and MNH outcomes [20,21,23,36,42,44,45,47-51]. The reviews varied in which MNH outcomes were investigated, especially in relation to community mobilization. The majority of the reviews used only ANC uptake ( $n=17)$, including three reviews that reported on early ANC $[39,42,45,55]$. The remaining reviews looked at ANC and PNC outcomes for the community mobilization interventions $(n=4)$ or only PNC $(n=1)$.

\section{Findings of community mobilization on ANC/PNC uptake}

Overall, reviews describe a positive association between community mobilization and ANC/PNC uptake. The ANC/PNC utilization outcomes documented by the reviews varied, perhaps explaining the dearth of meta-analyses conducted. Reviews described specific outcomes such as number of antenatal examinations [39], utilizing antenatal health facilities [44], or receiving at least one ANC visit $[39,42,45,51]$. Three of these reviews also investigated receiving at least three or four ANC visits $[39,42,45]$. The five reviews that stated PNC-specific outcomes described awareness of PNC [37] and postpartum care-seeking [21] or PNC check-ups for the mother and/or newborn $[41,49,53]$. The three reviews with studies that examined ANC in the first trimester reported on registration [39,42] and actual attendance [45]. Detailed findings of the reviews are presented in Appendix S4 in the Online Supplementary Document.

While it was not possible to synthesize results in meta-analyses due to high heterogeneity across included studies, 15 reviews reported at least one positive association between what they described as community mobilization activities and ANC and/or PNC uptake [20,21,23,36,38-40,42-45,47,48,51,53,54]. However, five reviews also presented primary studies that found no change or no statistically significant changes in ANC uptake despite the implementation of community mobilization interventions $[21,39,42,45,47]$ and one referenced a study that found a decrease in the "overall use of antenatal facilities" [44]. Though more limited, the findings on PNC uptake were also largely positive with two reviews describing significant increases in women attending PNC following the interventions $[49,53]$.

\section{Classification of community mobilization strategies to increase community support for ANC/PNC uptake}

The varying levels of detail presented in the reviews presented challenges in synthesizing findings across all reviews. The 12 reviews (13 papers) that described community mobilization and ANC/PNC in greater depth comprise the main focus for the rest of this publication. As demonstrated in Table 3, the reviews included in 

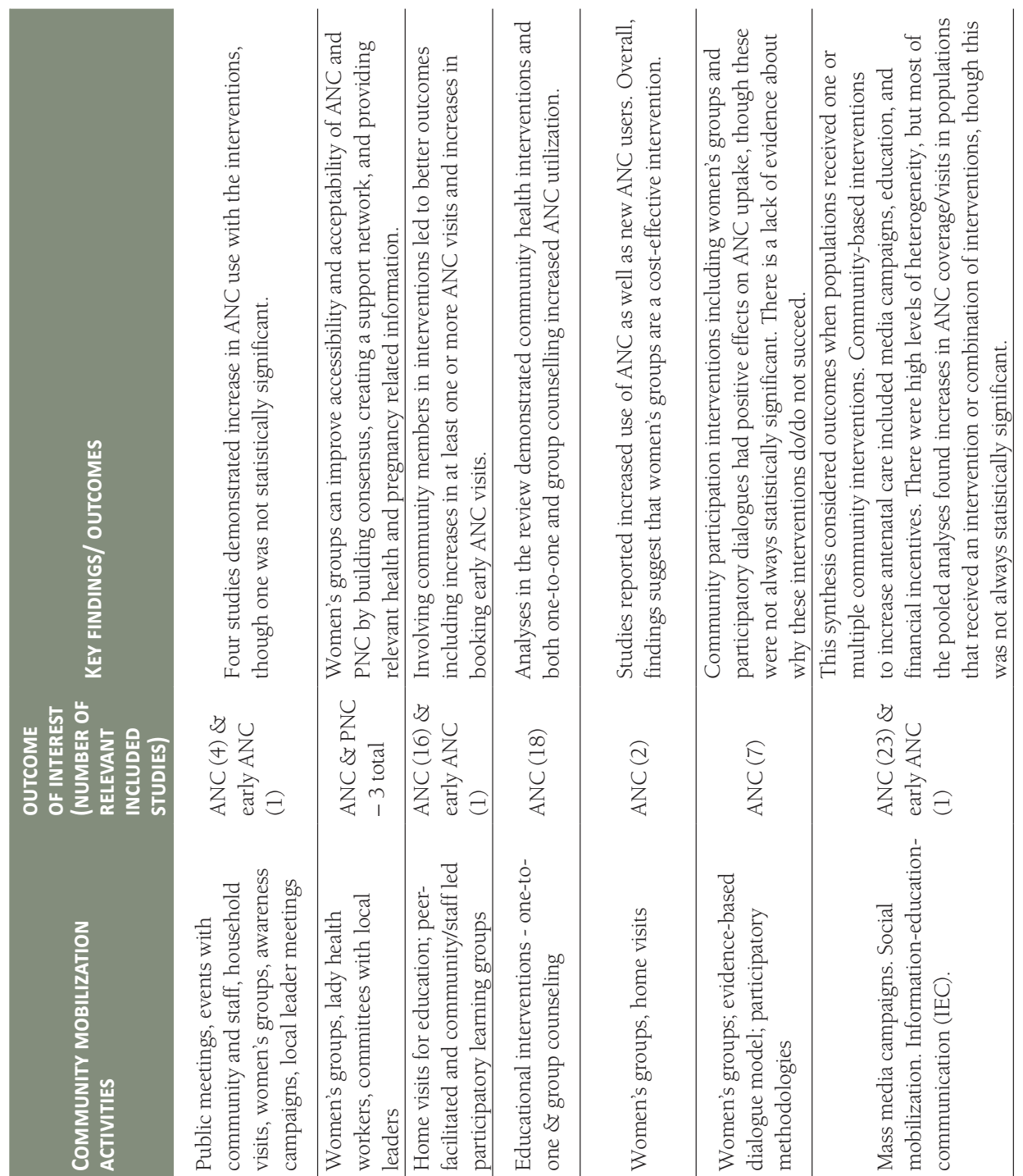

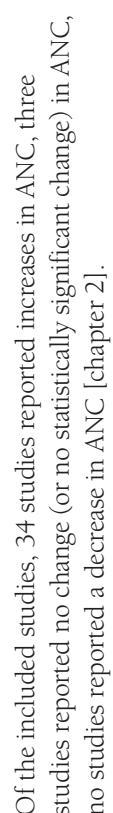

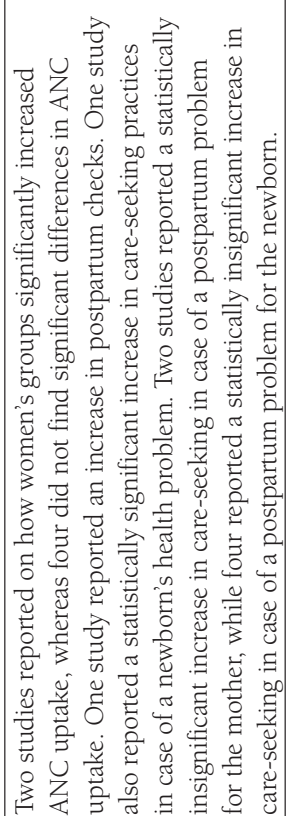

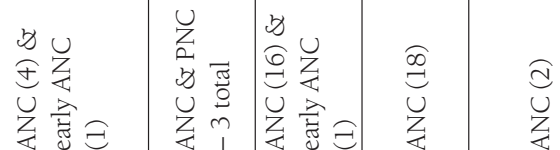

(1)

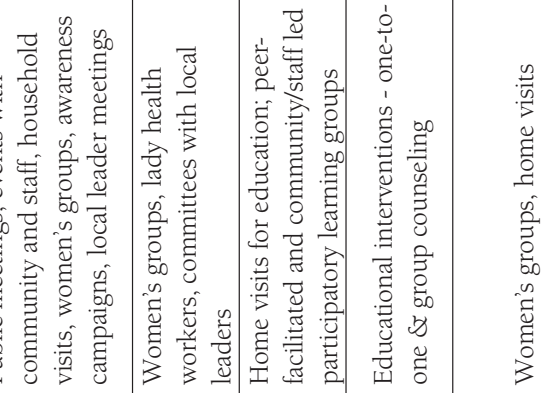

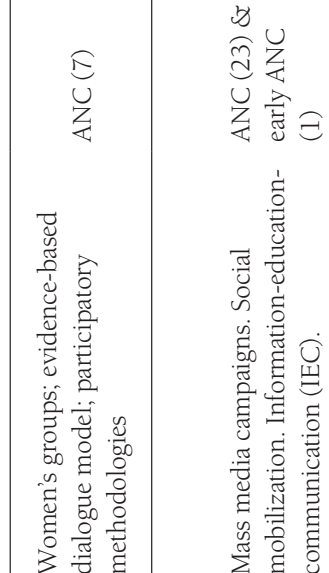

㻤芯

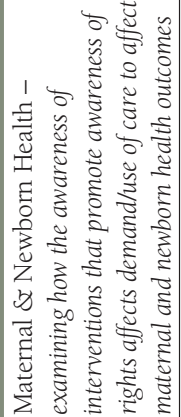

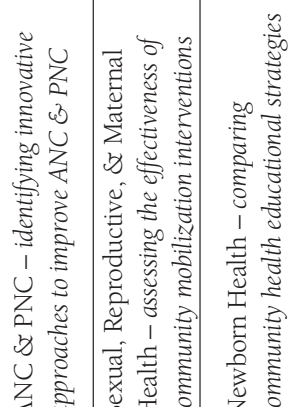

홀

है

蒂

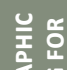

尊产愛

$\sum_{j}^{y}$

$\frac{\pi}{\frac{\pi}{0}}$

$\frac{\pi}{0}$

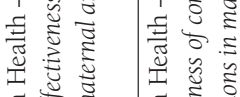

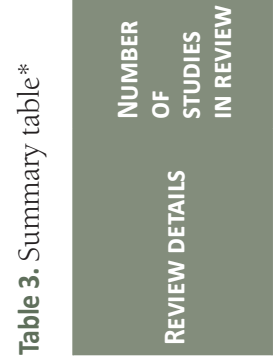

落产

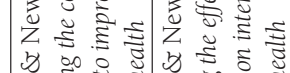

名

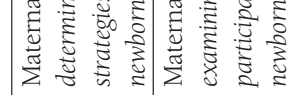

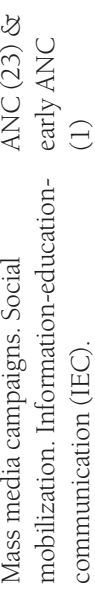

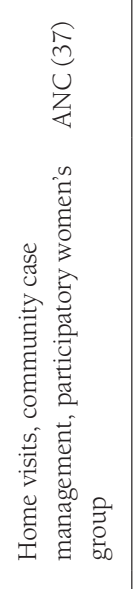

$y$

बढ

兄台

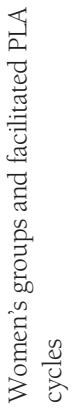

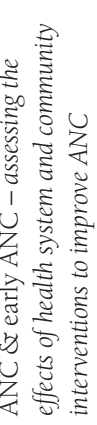

를 है

चี

ही है है

है है है

资

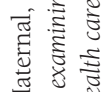

要

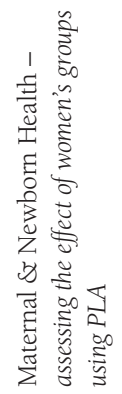

$\frac{\pi}{\frac{\pi}{0}}$

$\sum_{3}^{3}$

$\stackrel{3}{3}$

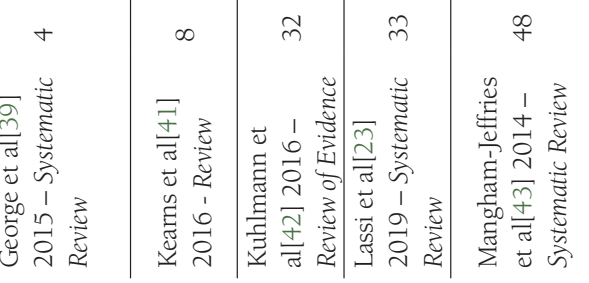

는

मे

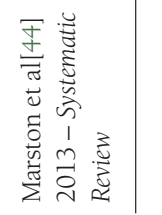

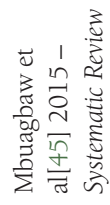

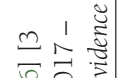

氙语

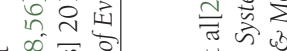

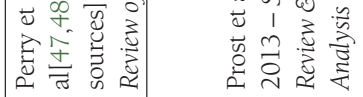




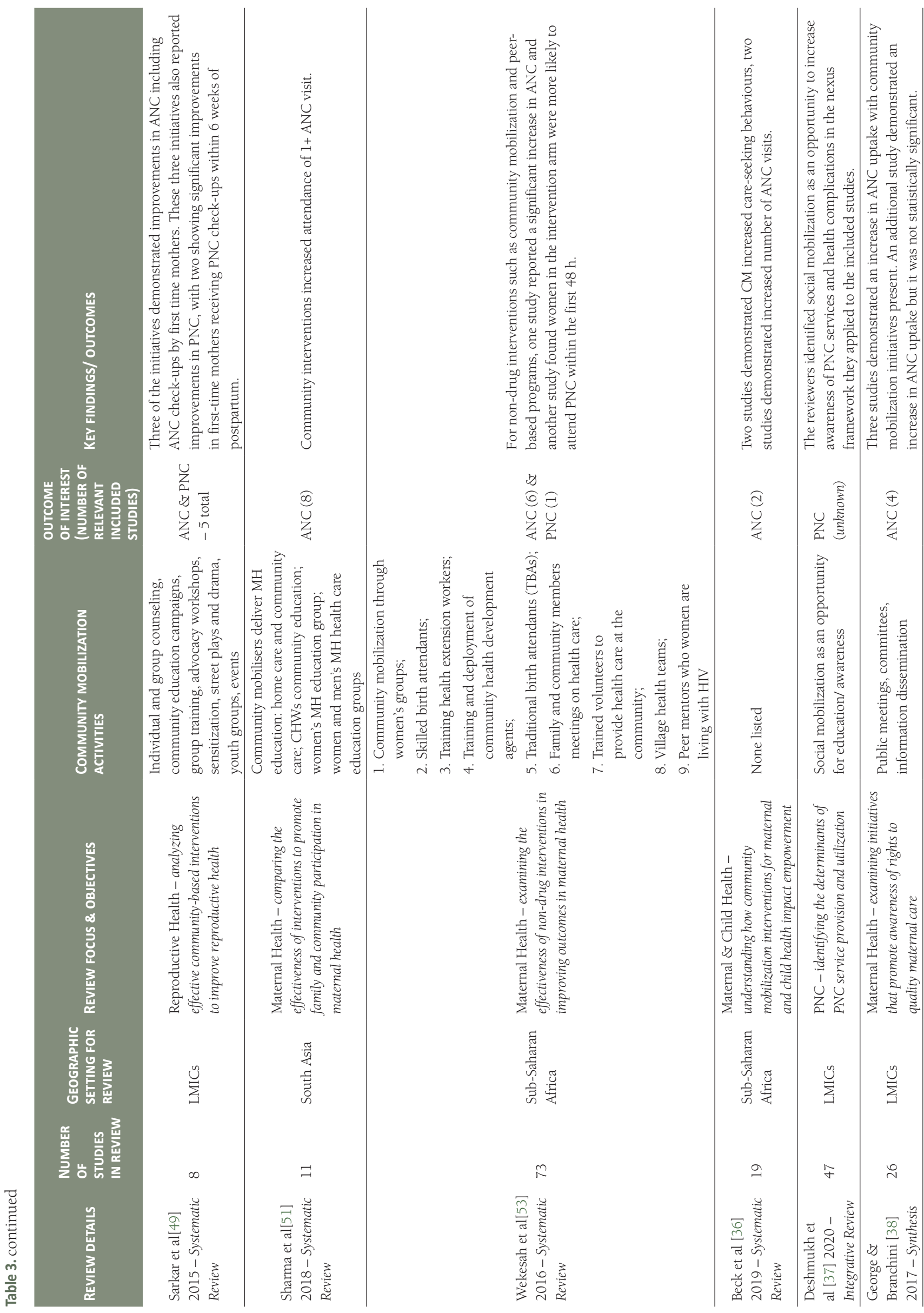




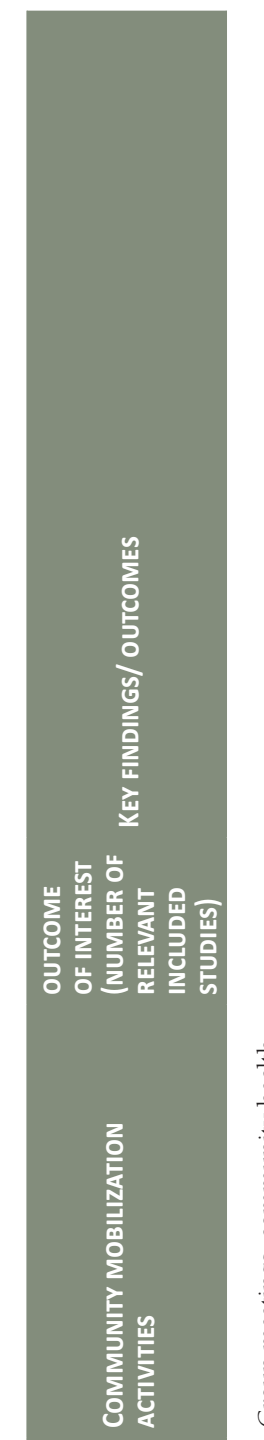

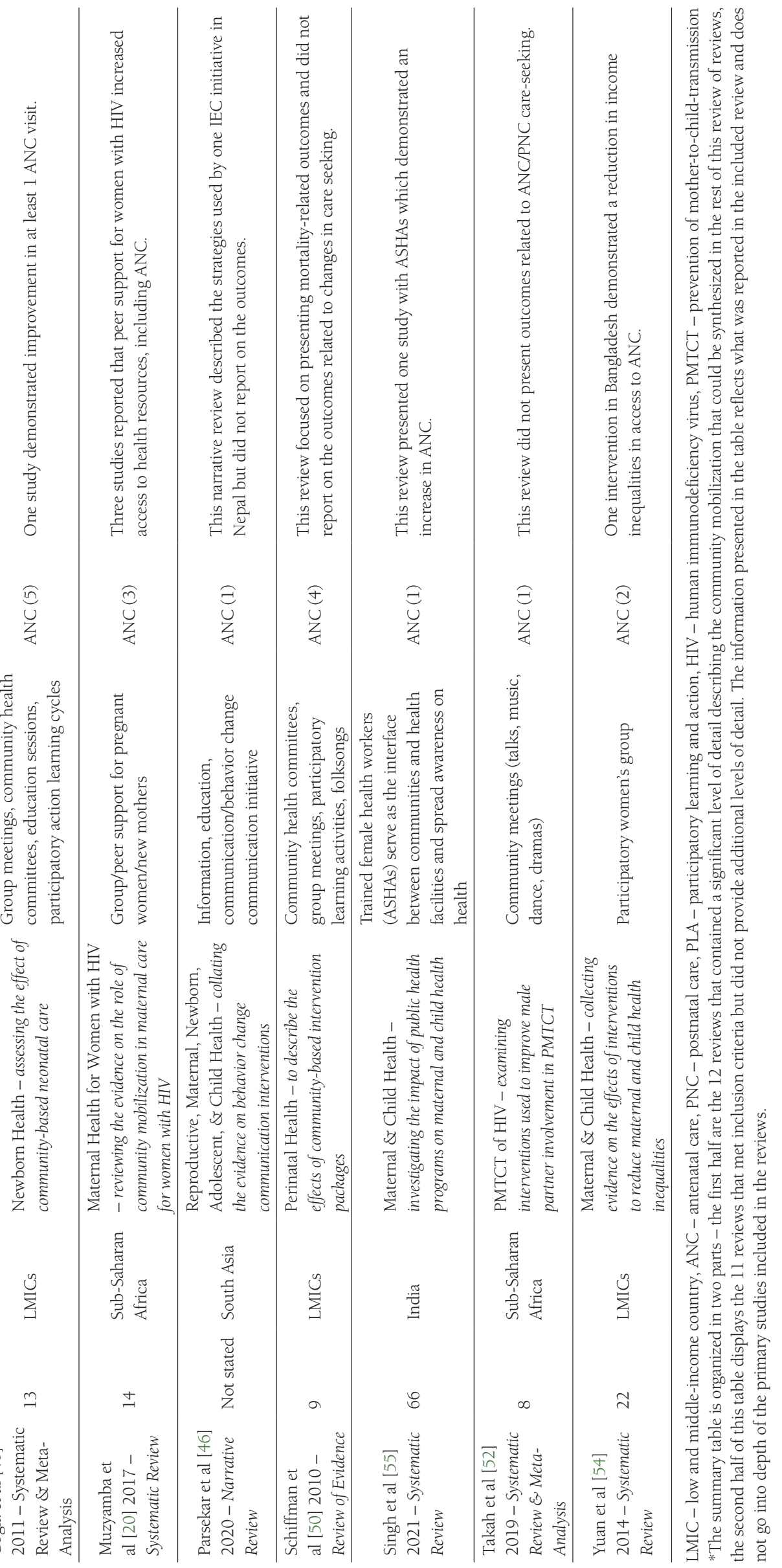


this analysis had a range of different stated objectives and the primary studies they synthesized would have also differed in their objectives and studied interventions. Four of the reviews focused on assessing interventions including community mobilization and/or participation [21,42,44,51], while the rest of the reviews did not specify a focus on community mobilization or considered community-based interventions more broadly.

Additionally, there are various definitions and levels of community mobilization; and an array of activities that are called community mobilization. This review of reviews highlights that heterogeneity as well. Strategies and activities described by the reviews ranged from passive communication to more active approaches that included involving community members or consulting local leaders. Table 4 displays the range of activities presented in the reviews as community mobilization strategies. The majority of included reviews did not go into depth on how these activities were implemented, such as the topics covered in meetings or the process of developing communication materials.

Table 4. Community mobilization strategies for ANC/PNC described in the included reviews with significant level of detail ( $\mathrm{n}=12$ )

\begin{tabular}{|c|c|c|c|}
\hline $\begin{array}{l}\text { RANGE/TYPE/ } \\
\text { LEVEL OF } \\
\text { MOBILIZATION }\end{array}$ & TYPE OF ACTIVITY & DESCRIPTION OF ACTIVITIES & REFERENCES \\
\hline \multirow{4}{*}{$\begin{array}{l}\text { These activities } \\
\text { place a focus on } \\
\text { problem solving } \\
\text { and finding } \\
\text { solutions. }\end{array}$} & $\begin{array}{l}\text { Community } \\
\text { health } \\
\text { committees }\end{array}$ & $\begin{array}{l}\text { Community health committees were set up as an opportunity to consult various } \\
\text { community members, collaborate, build consensus, and identify solutions to maternal } \\
\text { and newborn health problems. }\end{array}$ & $\begin{array}{l}\text { Kuhlmann et al [42], } \\
\text { Jennings et al [47] \& } \\
\text { Perry et al [48] }\end{array}$ \\
\hline & $\begin{array}{l}\text { Local leader } \\
\text { meetings }\end{array}$ & $\begin{array}{l}\text { Meetings with local leaders could be used in various forms at different time points in } \\
\text { an intervention. Some interventions engaged with local leaders at the start for buy- } \\
\text { in/involvement in initiatives such as women's groups or other community activities } \\
\text { while others had elected local leaders run community meetings with the public and } \\
\text { stakeholders. }\end{array}$ & $\begin{array}{l}\text { George et al [39], } \\
\text { Kearns et al }[41] \\
\text { Perry et al }[47,48]\end{array}$ \\
\hline & & $\begin{array}{l}\text { These activities included groups which met on a regular or recurring basis to discuss and } \\
\text { address maternal health issues. }\end{array}$ & $\begin{array}{l}\text { George et al [39], Kearns } \\
\text { et al [41], Marston et al }\end{array}$ \\
\hline & $\begin{array}{l}\text { Recurrent } \\
\text { groups }\end{array}$ & $\begin{array}{l}\text { This included women's groups led by volunteers as well as groups using the PLA cycle } \\
\text { where a trained facilitator led regularly scheduled meetings. These recurrent groups } \\
\text { often utilized participatory activities that were used to identify and adopt strategies in the } \\
\text { community to improve maternal health. }\end{array}$ & $\begin{array}{l}\text { [44], Mbuagbaw et al } \\
\text { [45], Mangham-Jeffries } \\
\text { et al [43], Perry et al } \\
\text { [47,48], Prost et al [21] }\end{array}$ \\
\hline \multirow{3}{*}{$\begin{array}{l}\text { These activities } \\
\text { involve } \\
\text { participatory } \\
\text { techniques } \\
\text { to mobilize } \\
\text { communities } \\
\text { for immediate } \\
\text { action. }\end{array}$} & Peer mentors & $\begin{array}{l}\text { Peer mentors or peer counsellors were used to provide education, advice, and support } \\
\text { to pregnant women and families. They often used participatory learning activities } \\
\text { or community dialogues to encourage community action. One example of peer } \\
\text { mentors called "Care Groups" used facilitators to share health education that volunteer } \\
\text { participants could then disseminate to mothers in their surrounding households[48] }\end{array}$ & $\begin{array}{l}\text { Kuhlmann et al }[42] \\
\text { Mangham-Jeffries et al } \\
{[43], \text { Perry et al }[47,48]}\end{array}$ \\
\hline & $\begin{array}{l}\text { Public/ } \\
\text { community } \\
\text { meetings }\end{array}$ & $\begin{array}{l}\text { Larger community gatherings where trained volunteers or health care workers provided } \\
\text { information and education as well as identified community action plans and priorities. } \\
\text { Various strategies and activities were employed at these community awareness meetings } \\
\text { including: street plays, dramas, dances, music, folksongs, skits, games, and other } \\
\text { participatory learning activities and methods. }\end{array}$ & $\begin{array}{l}\text { George et al [39], } \\
\text { Mbuagbaw et al [45], } \\
\text { Perry et al }[47,48] \text {, } \\
\text { Sarkar et al [49], } \\
\text { Sharma et al [51] }\end{array}$ \\
\hline & $\begin{array}{l}\text { Advocacy } \\
\text { workshops } \\
\& \text { special } \\
\text { community } \\
\text { events }\end{array}$ & $\begin{array}{l}\text { Public education and advocacy activities were often held to increase demand for } \\
\text { maternal health services. This included special community events such as health fairs } \\
\text { and celebration days to promote awareness and encourage community support for health } \\
\text { interventions. For example, one study reported women's groups encouraging attendance } \\
\text { at "Mamta Divas" which were special event village health and nutrition days for mothers } \\
\text { and children[39]. }\end{array}$ & $\begin{array}{l}\text { George et al [39], } \\
\text { Sarkar et al [49], } \\
\text { Sharma et al [51] }\end{array}$ \\
\hline \multirow{3}{*}{$\begin{array}{l}\text { These activities } \\
\text { involve } \\
\text { informing } \\
\text { or educating } \\
\text { communities. }\end{array}$} & $\begin{array}{l}\text { Mass media } \\
\& \text { awareness } \\
\text { campaigns }\end{array}$ & $\begin{array}{l}\text { Mass media and awareness campaigns were conducted through media forums such as } \\
\text { radio, television, newspapers, cellular phone messages and printed materials such as } \\
\text { posters, brochures, and banners as well as live events such as street theatre. The aim of } \\
\text { these interventions was often to inform the community and pregnant women in order to } \\
\text { improve health service utilization, such as ANC and PNC. }\end{array}$ & $\begin{array}{l}\text { George et al, Lassi et al, } \\
\text { Mbuagbaw et al [45] }\end{array}$ \\
\hline & $\begin{array}{l}\text { Women \& } \\
\text { men's maternal } \\
\text { health education } \\
\text { sessions }\end{array}$ & $\begin{array}{l}\text { Community mobilisers, health care workers, and midwives held focus groups with } \\
\text { community members or visited households to discuss and educate both men and } \\
\text { women on maternal health. These activities were conducted by both men and women } \\
\text { community mobilisers. Also defined as "group counselling." [23] }\end{array}$ & $\begin{array}{l}\text { Lassi et al [23], } \\
\text { Mangham-Jeffries et al } \\
\text { [43], Sharma et al [51] }\end{array}$ \\
\hline & $\begin{array}{l}\text { Home visits+ } \\
\text { (as a component } \\
\text { of larger } \\
\text { intervention } \\
\text { package) }\end{array}$ & $\begin{array}{l}\text { While home visits alone are not typically considered a community mobilization activity } \\
\text { on their own, many of the reviews and studies described home visits as a component } \\
\text { of community-based interventions and one of the objectives of the visit was to mobilize } \\
\text { family support for MNH. Sessions aimed used to provide interactive education as well as } \\
\text { support for care seeking for health services as well as improve household care practices. } \\
\text { These were conducted by community health workers, community organizers, or peer } \\
\text { counsellors. Also defined as "one-to-one counselling." [23] }\end{array}$ & $\begin{array}{l}\text { George et al [39], } \\
\text { Kuhlmann et al } \\
\text { [42], Lassi et al [23], } \\
\text { Mangham-Jeffries et al } \\
\text { [43], Mbuagbaw et al } \\
\text { [45], Perry et al }[47,48] \\
\text { Wekesah et al [53] }\end{array}$ \\
\hline
\end{tabular}

ANC - antenatal care, PNC - postnatal care, PLA - participatory and learning action, MNH - maternal and newborn health 


\section{Community mobilization strategies to increase community support for early ANC}

Three reviews included one study each that identified early use of ANC as an outcome. The findings and strategies presented by the relevant primary studies are summarized below. George et al. described a study using discussions and participatory exercises in women's groups to develop a monitoring tool for maternal health care [39]. The tool was shared with local leaders and stakeholders to develop plans of action to improve the quality of maternal health services [57]. ANC registration in the first trimester increased in both communities where this programme was implemented - from $31.4 \%$ to $54.3 \%$ in Dhabva and from $17 \%$ to $41.8 \%$ in Sevaniya [57]. Mbuagbaw et al. reported on a study by Wu et al. that used a multipart intervention to train midwives, inform communities on ANC, and provide basic medical resources to improve ANC and therefore MNH outcomes [45,58]. The trained midwives distributed print materials such as letters, leaflets, and educational posters promoting ANC [58]. However, in combination with the other components of the intervention, this program did not improve uptake of ANC earlier in pregnancy [45]. The final study included in Kuhlman et al. focused on community-based interventions to conduct trainings for community members and birth attendants led by government officials and local community leaders [59]. While the primary focus of the study was on newborn mortality, they also reported an increase in scheduled ANC visits for primigravida women in the first 16 weeks of pregnancy (from $18.75 \%$ to $56.9 \%, P<0.001$ ) [42].

\section{Factors influencing ANC uptake and community mobilization}

A recent qualitative evidence synthesis on uptake of routine ANC, conducted to inform the development of WHO's ANC recommendations, identified 52 factors (perceptions or experiences of women and health care providers) across three overarching domains (behavioral beliefs, normative beliefs, and control beliefs) that influenced the initial or continued use of ANC [27]. Appendix S5 in the Online Supplementary Document exhibits how 25 of these factors can be influenced by or supported with community mobilization based on insights from the included reviews. Using the evidence, the synthesis developed a logic model based on the theory of planned behavior to map how individual and social beliefs and norms influenced women's decisions to attend ANC regularly [27,34]. This model depicts how background factors that extend beyond the individual, influence women's beliefs, attitudes, and finally behaviours regarding ANC (and potentially PNC) [11,27]. In order to provide more pragmatic insight from the findings of this review of reviews, we considered where community mobilization can influence the pathway described by the positive feedback loop logic model. Figure 2

\section{Where community mobilization can increase family and community support for ANC/PNC}

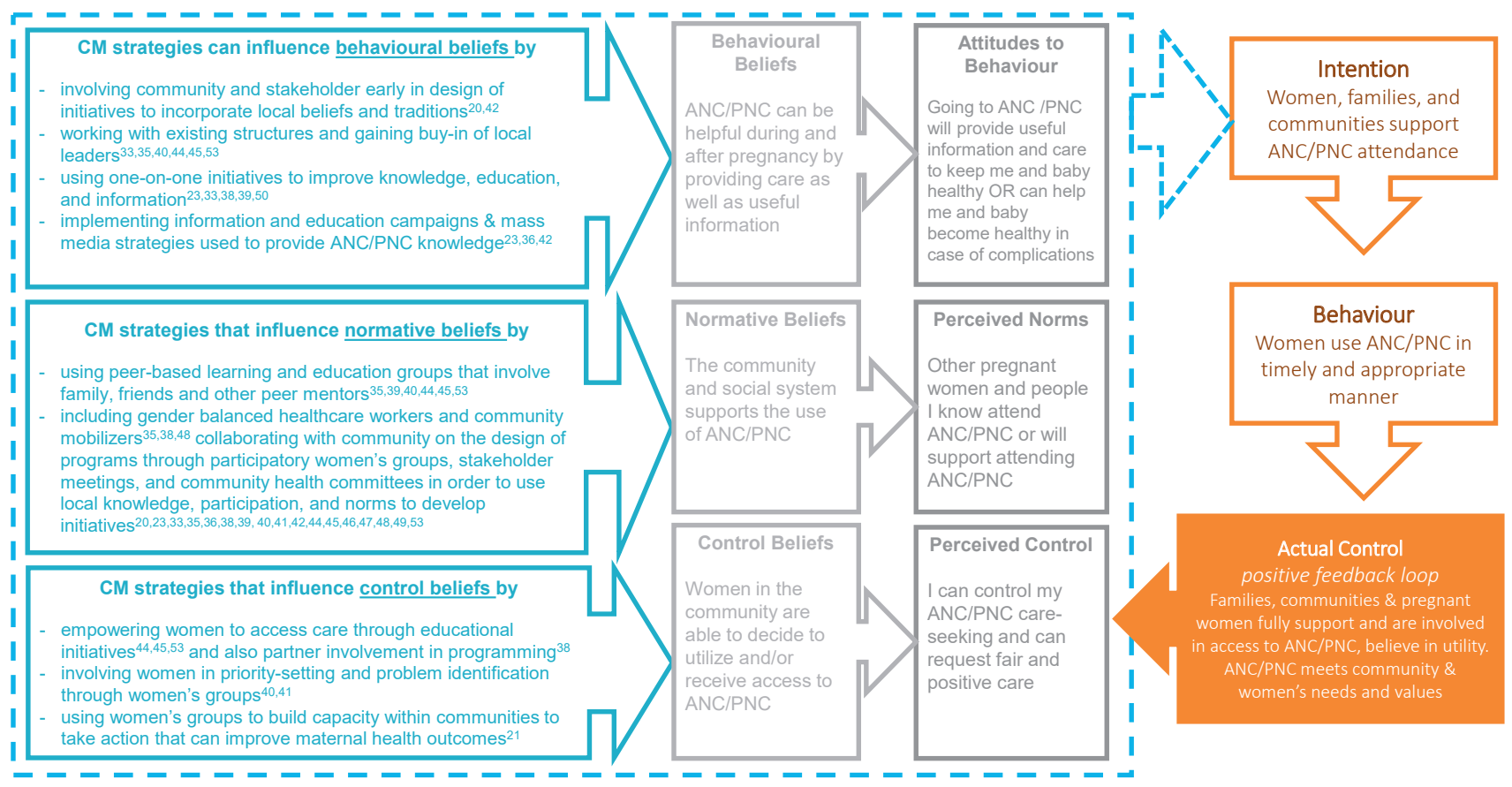

Figure 2. Logic model mapping. The logic model includes "What do people believe in this context (behavioral beliefs)?'; 'What is normal in this context' (normative beliefs)? and 'How much control do we have over what happens here' (control beliefs)?; the attitudes and perceptions predicted by these beliefs; the intended behavior that could result; and the actual experiences" [27] and cyclical feedback loop that connects all of these components. 
illustrates what components and strategies from community mobilization activities can influence behavioral beliefs, normative beliefs, and control beliefs which would increase community support for ANC/PNC uptake.

Behavioral beliefs may be influenced by the information and knowledge individuals have. Community mobilization strategies that focus on information, education, communication, and awareness can influence these initial behavioral beliefs by providing additional information. However, reviews also highlight the importance of incorporating local knowledge and tradition into these methods and communication materials $[20,45]$. Normative beliefs are swayed by social and community influences, highlighting the relevance of community mobilization strategies that target not only pregnant and postpartum women but also the partner, their family and friends. Societal norms such as power, family dynamics, and gender-balances must be considered in the program design $[38,41,51]$. Participatory methodologies that include women, parents, local leaders, and community stakeholders can incorporate local knowledge and norms in the development of initiatives $[20,23,36,38,39,41-45,47-52]$. Beliefs about the level of control individuals have are where empowerment of individuals, and particularly pregnant and postpartum women and parents, becomes more impactful. This stream goes beyond the involvement and consultation of pregnant women. Parents and the community by a particular program to a sustainable and continued capacity for community members to identify and participate in addressing challenges. A range of community mobilization activities can influence control beliefs to empower women and parents beginning with education to establishing women's groups that focus on maternal and child health activities [21].

\section{DISCUSSION}

The objective of this review of reviews was to identify community mobilization strategies used to support appropriate and timely use of ANC (including early access in the first trimester) and PNC in LMICs. This review of reviews identified 23 publications representing 22 reviews that described using community mobilization to influence ANC/PNC uptake. The reviews ranged in their methods, objectives, and descriptions of community mobilization strategies as well as their definitions of early ANC (12 vs 16 weeks). Overall, the majority of studies noted the importance of community mobilization in delivering or improving support for ANC/PNC uptake either as a main intervention or within a package of interventions. However, reviews largely focused on the statistical outcomes of including a "community mobilization component" such as changes in uptake of services or mortality rates. While many of these reviews stated or implied an element of community mobilization was present, they often did not describe in sufficient detail what this process entailed or how it was implemented [19]. As a result, the majority of reported findings in the literature highlight community mobilization's positive influence on ANC/PNC use, but lack information on the processes to explain this association. This review of reviews details positive findings relating to community mobilization to improve family and community support for ANC/PNC, but it is difficult to make more specific recommendations due to little insight into how or why these approaches work.

The logic model presented by the Downe et al. qualitative evidence synthesis and adapted in Figure 2 provides a lens to understand what is happening between the external intervention and the final outcome of using ANC/PNC. Community mobilization activities can influence this pathway through targeted interventions that influence behavioral, normative, and control beliefs. Information-education-communication (IEC) approaches target behavioral beliefs by using public health education or communication to affect behavior change in a population [60]. In line with a range of community-related strategies, it is important to incorporate community norms and beliefs and work with community leaders in the development and implementation of IEC [60]. One example rolled out for child health in South Asia is the UNICEF Meena Communication Platform that used the animated character of "Meena", a young South Asian girl, to communicate important health messaging in an entertaining and relatable format [46,61]. Adapting community mobilization strategies through the involvement of local stakeholders in the design process enables the contextualization of materials and programming $[20,38,45]$.

This involvement of community members can extend to the inclusion of women and families through participatory activities and peer groups that are implemented in ways that respect societal norms. A methodology described by multiple reviews is the Warmi methodology, first introduced by Save the Children in Bolivia in 1990 [62]. This multi-step PLA cycle used in women's groups not only provided beneficial peer support, but also empowered women to make decisions and take action to implement local solutions for the challenges they faced in regards to their and their baby's health $[21,38,63]$. Through the Warmi project, women played an active role in planning how their own priorities would be addressed by developing educational materials and strategies alongside local authorities, as well as continued involvement of the community and women through participatory evaluation practices $[40,44,64,65]$. Community health committees also use a collaborative ap- 
proach to increase local programme ownership and therefore community empowerment [66]. By working directly with local communities, initiatives to improve community support for ANC/PNC place power and responsibility in these communities. This belief and perception of control plays a role in the uptake logic model feedback loop both on an individual and community level [27,34].

These findings have implications for practice, policy, and research. As established in the literature, a range of factors influence the utilization of appropriate and timely ANC/PNC [7,8,11,27,67-69]. Often these are community-related factors which have supported the use of community mobilization to enable community action and contribute to improved MNH [70-72]. The adapted logic model demonstrates opportunities for community mobilization strategies to influence the perceptions and experiences of communities in regards to support for ANC/PNC [27]. As highlighted by this review of reviews, a range of activities and programs have been implemented across scales and settings. However, the complexity of these interventions as well as the lack of information on implementation processes advocate for further studies that provide this additional detail on community mobilization's implications for ANC/PNC support and uptake. Reviews published as recently as 2021 perpetuate the same pattern by labeling one-sided didactic programs as "community participation" or failing to describe what comprised the community mobilization component of a program $[73,74]$. Furthermore, while the reviews show a large geographic range in terms of countries and SDG regions included, the relevance of context in community-based interventions emphasizes the importance of considering localized and country/region-specific findings. This is especially important when applying lessons learned from global trends across settings.

Notably, barriers and facilitators are different across contexts making these programs a complex health intervention which could benefit from being considered through an implementation science or complexity science lens [75]. Implementation science methodologies could provide a systems-level consideration of the processes of community mobilization, rather than a positivist approach reporting on binary outcomes [76,77]. In order to learn from the experiences of community mobilization strategies and implement them in new or future settings, there is a need to understand generative causation and how these programs work for individuals and families within social systems [78]. In order to have a sustainable impact, community mobilization inherently relies on varying levels of systems as well as inter-related decision-making and behaviours of individuals and groups that form dynamic feedback loops and dependencies [13,76,79]. This implementation science lens can be used to account for the dynamic nature of these interventions to inform the translation of findings into recommendations for policy and practice [76,77].

\section{Strengths and limitations}

By analyzing literature at the review level, this paper provides a comprehensive overview of the existing evidence and highlights implications for policy and practice as well as research gaps. Notably, this review of reviews emphasizes how the current descriptions of incorporating these community mobilization activities are often limited in detail or a brief sentence in a publication's methodology section. There is a need to document and learn from the processes of community mobilization strategies when they are implemented, often within larger MNH packages. However, in order to do this and guide eventual implementation this review of reviews also calls for programmers and researchers to clearly define and explain the strategies and processes used to mobilize a community. Table 4 provided above may serve as a starting point.

The high heterogeneity of review designs made it challenging to synthesize findings across a varied range of interventions and outcomes. This heterogeneity comes from the variety of review objectives, activities, and reported metrics and outcomes. The included reviews presented varying levels of detail in their findings - some reviews reported specific study results, while others alluded to groups of studies more generally. Additionally, as this is a review of reviews, some primary studies were represented in multiple reviews which may have emphasized or over-represented some individual studies' findings. Finally, ANC and PNC were often not the main focus of the reviews. Many reviews considered sexual and reproductive or maternal, newborn, and child health more broadly with ANC/PNC as one component or outcome. As a result, increasing community support for ANC/PNC specifically was often not the main focus of the interventions and strategies they described. This implies community mobilization activities described in this review cannot be simply extrapolated to improve ANC/PNC uptake, but they will need to be part of broader MNH programme strategy as demonstrated by many of the included studies $[17,18]$.

\section{A call for action and clarity}

Since the Alma Ata Declaration that prioritized community participation in health care, programs and policies that include community members in all aspects of health care have been widely advocated for within MNH [80]. Community mobilization approaches are amongst these strategies and are designed to give the community 
an opportunity to contribute to improved $\mathrm{MNH}$ and increase community support for appropriate and timely use of ANC and PNC and contribute to empowering women, parents and communities. These actions are not just an add-on to health interventions but is a right that must be unequivocally integrated into any initiative. Additionally, the range of community mobilization strategies can also shape the behavioral, normative, and control beliefs of both individuals and communities - influencing the pathways in the logic model for uptake of timely and appropriate ANC/PNC.

Community-based interventions, and particularly community mobilization approaches are emphasized in MNH programmes throughout different global strategies. Yet, this review affirms that there is little consistency in what this means, how it is implemented and poor documentation that allows us to understand and appreciate what has been done and what was the effect [81]. As noted in previous reviews and the literature, there is ambiguity surrounding the various definitions and what qualifies as "community mobilization," and there is often overlap with additional terms such as "community engagement," "community consultation," or "community participation" $[20,81,82]$. These differing terminologies reflect the complex and dynamic nature of "community-(engagement/mobilization/participation)" [81-83]. These findings therefore calls for those in the field to harmonize definitions of this work, and to more robustly document and report the operationalization and processes by using reporting standards such as the WHO Programme Reporting Standards for sexual, reproductive, maternal, newborn, child and adolescent health [84]. This documentation can then guide and support evidence-informed implementation of community strategies for ANC/PNC as well as wider maternal and child health.

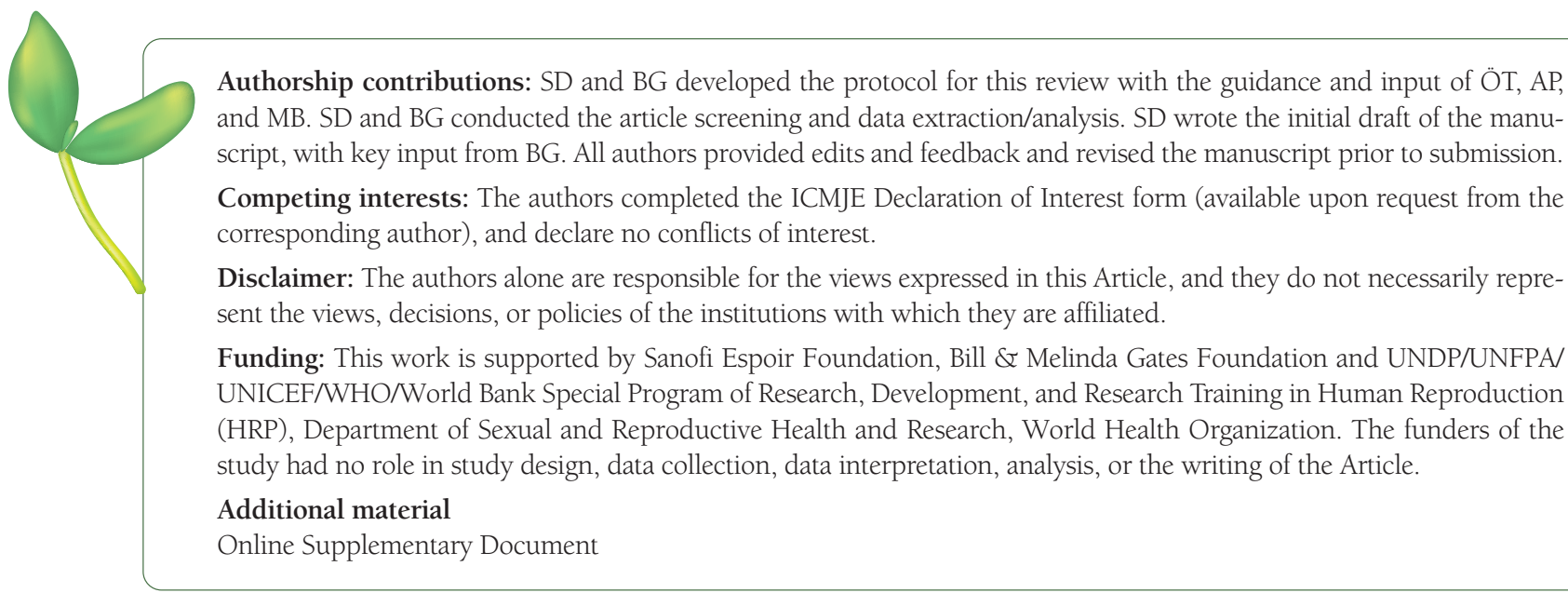

o Goals. Health Equity. 2019;3:145-54. Medline:31289773 doi:10.1089/heq.2018.0082

1 Yaya S, Ghose B. Global Inequality in Maternal Health Care Service Utilization: Implications for Sustainable Development

2 Tunçalp Ö, Pena-Rosas J, Lawrie T, Bucagu M, Oladapo O, Portela A, et al. WHO recommendations on antenatal care for a positive pregnancy experience_-going beyond survival. BJOG. 2017;124:860-2. Medline:28190290 doi:10.1111/14710528.14599

3 World Health Organization. Postnatal care for mothers and newborns: Highlights from the World Health Organization 2013 Guidelines. WHO: Geneva, Switzerland. 2015:1-8.

4 World Health Organization. WHO recommendations on postnatal care of the mother and newborn. Geneva: WHO; 2014.

5 Lattof SR, Moran AC, Kidula N, Moller A-B, Jayathilaka CA, Diaz T, et al. Implementation of the new WHO antenatal care model for a positive pregnancy experience: a monitoring framework. BMJ Glob Health. 2020;5:e002605. Medline:32565442

6 World Health Organization. WHO recommendations on antenatal care for a positive pregnancy experience. Geneva: WHO; 2016.

7 Downe S, Finlayson K, Walsh D, Lavender T. 'Weighing up and balancing out': a meta-synthesis of barriers to antenatal care for marginalised women in high-income countries. BJOG. 2009;116:518-29. Medline:19250363 doi:10.1111/j.14710528.2008.02067.x

8 Simkhada B. Teijlingen ERv, Porter M, Simkhada P. Factors affecting the utilization of antenatal care in developing countries: systematic review of the literature. J Adv Nurs. 2008;61:244-60. Medline:18197860 doi:10.1111/j.1365-2648.2007.04532.x

9 Callister LC, Edwards JE. Sustainable Development Goals and the Ongoing Process of Reducing Maternal Mortality. J Obstet Gynecol Neonatal Nurs. 2017;46:e56-64. Medline:28286075 doi:10.1016/j.jogn.2016.10.009

10 Langlois ÉV, Miszkurka M, Ziegler D, Karp I, Zunzunegui MV. Protocol for a systematic review on inequalities in postnatal care services utilization in low- and middle-income countries. Syst Rev. 2013;2:55. Medline:23830501 doi:10.1186/2046-4053-2-55 
11 Munabi-Babigumira S, Glenton C, Lewin S, Fretheim A, Nabudere H. Factors that influence the provision of intrapartum and postnatal care by skilled birth attendants in low-and middle-income countries: a qualitative evidence synthesis. Cochrane Database Syst Rev. 2017;CD011558. Medline:29148566 doi:10.1002/14651858.CD011558.pub2

12 Lassi ZS, Kumar R, Bhutta ZA. Community-Based Care to Improve Maternal, Newborn, and Child Health. In: Black RE, Laxminarayan R, Temmerman M, Walker N, editors. Reproductive, Maternal, Newborn, and Child Health: Disease Control Priorities, Third Edition (Volume 2). Washington (DC): The International Bank for Reconstruction and Development / The World Bank; 2016.

13 Tedrow VA, Zelaya CE, Kennedy CE, Morin SF, Khumalo-Sakutukwa G, Sweat MD, et al. No "magic bullet": exploring community mobilization strategies used in a multi-site community based randomized controlled trial: Project Accept (HPTN 043). AIDS Behav. 2012;16:1217-26. Medline:21822627 doi:10.1007/s10461-011-0009-9

14 Treno AJ, Holder HD. Community mobilization: evaluation of an environmental approach to local action. Addiction. 1997;92:S173-87. Medline:9231443 doi:10.1111/j.1360-0443.1997.tb02990.x

15 World Health Organization. An evidence map of social, behavioural and community engagement interventions for reproductive, maternal, newborn and child health. Geneva: WHO; 2017.

16 Rosato M. A framework and methodology for differentiating community intervention forms in global health. Community Dev J. 2015;50:244-63. doi:10.1093/cdj/bsu041

17 World Health Organization. WHO recommendations on health promotion interventions for maternal and newborn health 2015. Geneva: WHO; 2015.

18 World Health Organization. WHO recommendation on community mobilization through facilitated participatory learning and action cycles with women's groups for maternal and newborn health. Geneva: WHO; 2014.

19 Altman L, Kuhlmann AKS, Galavotti C. Understanding the black box: A systematic review of the measurement of the community mobilization process in evaluations of interventions targeting sexual, reproductive, and maternal health. Eval Program Plann. 2015;49:86-97. Medline:25615599 doi:10.1016/j.evalprogplan.2014.11.010

20 Muzyamba C, Groot W, Tomini SM, Pavlova M. The role of Community Mobilization in maternal care provision for women in sub-Saharan Africa- A systematic review of studies using an experimental design. BMC Pregnancy Childbirth. 2017;17:274. Medline:28851299 doi:10.1186/s12884-017-1458-6

21 Prost A, Colbourn T, Seward N, Azad K, Coomarasamy A, Copas A, et al. Women's groups practising participatory learning and action to improve maternal and newborn health in low-resource settings: A systematic review and meta-analysis. Lancet. 2013;381:1736-46. Medline:23683640 doi:10.1016/S0140-6736(13)60685-6

22 Lassi ZS, Bhutta ZA. Community-based intervention packages for reducing maternal and neonatal morbidity and mortality and improving neonatal outcomes. Cochrane Database Syst Rev. 2015;CD007754. Medline:25803792 doi:10.1002/14651858. CD007754.pub3

23 Lassi ZS, Kedzior SG, Bhutta ZA. Community-based maternal and newborn educational care packages for improving neonatal health and survival in low-and middle-income countries. Cochrane Database Syst Rev. 2019;CD007647. Medline:31686427 doi:10.1002/14651858.CD007647.pub2

24 Nyamtema AS, Urassa DP, van Roosmalen J. Maternal health interventions in resource limited countries: a systematic review of packages, impacts and factors for change. BMC Pregnancy Childbirth. 2011;11:30. Medline:21496315 doi:10.1186/14712393-11-30

25 Scott K, Beckham SW, Gross M, Pariyo G, Rao KD, Cometto G, et al. What do we know about community-based health worker programs? A systematic review of existing reviews on community health workers. Hum Resour Health. 2018;16:39. Medline:30115074 doi:10.1186/s12960-018-0304-x

26 Bucagu M, Kagubare JM, Basinga P, Ngabo F, Timmons BK, Lee AC. Impact of health systems strengthening on coverage of maternal health services in Rwanda, 2000-2010: a systematic review. Reprod Health Matters. 2012;20:50-61. Medline:22789082 doi:10.1016/S0968-8080(12)39611-0

27 Downe S, Finlayson K, Tunçalp Ö, Gülmezoglu AM. Provision and uptake of routine antenatal services: a qualitative evidence synthesis. Cochrane Database Syst Rev. 2019;CD012392. Medline:31194903 doi:10.1002/14651858.CD012392.pub2

28 Hasanpoor E, Hallajzadeh J, Siraneh Y, Hasanzadeh E, Haghgoshayie E. Using the Methodology of Systematic Review of Reviews for Evidence-Based Medicine. Ethiop J Health Sci. 2019;29:775-8. Medline:31741649

29 Hunt H, Pollock A, Campbell P, Estcourt L, Brunton G. An introduction to overviews of reviews: planning a relevant research question and objective for an overview. Syst Rev. 2018;7:39. Medline:29490699 doi:10.1186/s13643-018-0695-8

30 Joanna Briggs Institute. The Joanna Briggs institute reviewers' manual 2014 methodology for JBI umbrella reviews. Adelaide: The Joanna Briggs Institute. 2014.

31 Aromataris E, Fernandez R, Godfrey CM, Holly C, Khalil H, Tungpunkom P. Summarizing systematic reviews: methodological development, conduct and reporting of an umbrella review approach. JBI Evid Implement. 2015;13.

32 Smith V, Devane D, Begley CM, Clarke M. Methodology in conducting a systematic review of systematic reviews of healthcare interventions. BMC Med Res Methodol. 2011;11:15. Medline:21291558 doi:10.1186/1471-2288-11-15

33 Checklist for Systematic Reviews and Research Syntheses: Joanna Briggs Institute; 2017 Available: https://jbi.global/sites/default/files/2019-05/JBI_Critical_Appraisal-Checklist_for_Systematic_Reviews2017_0.pdf. Accessed: 1 August 2021.

34 Azjen I. The theory of planned behavior. Organ Behav Hum Decis Process. 1991;50:179-211. doi:10.1016/07495978(91)90020-T

35 Moher D, Liberati A, Tetzlaff J, Altman DG. The PG. Preferred Reporting Items for Systematic Reviews and Meta-Analyses: The PRISMA Statement. PLoS Med. 2009;6:e1000097. Medline:19621072 doi:10.1371/journal.pmed.1000097 
36 Beck DC, Munro-Kramer ML, Lori JR. A scoping review on community mobilisation for maternal and child health in sub-Saharan Africa: Impact on empowerment. Glob Public Health. 2019;14:375-95. Medline:30182808 doi:10.1080/17441692.2 018.1516228

37 Deshmukh V, John S, Arora NK. Utilization of Postnatal Healthcare Services Delivered through Home Visitation and Health Facilities for Mothers and Newborns: An Integrative Review from Developing Countries. Indian J Pediatr. 2020;87:207-16. Medline:31900850 doi:10.1007/s12098-019-03101-4

38 George AS, Branchini C. Principles and processes behind promoting awareness of rights for quality maternal care services: a synthesis of stakeholder experiences and implementation factors. BMC Pregnancy Childbirth. 2017;17:264. Medline:28854888 doi:10.1186/s12884-017-1446-x

39 George AS, Branchini C, Portela A. Do Interventions that Promote Awareness of Rights Increase Use of Maternity Care Services? A Systematic Review. PLoS One. 2015;10:e0138116. Medline:26444291 doi:10.1371/journal.pone.0138116

40 Gogia S, Ramji S, Gupta P, Gera T, Shah D, Mathew JL, et al. Community based newborn care: A systematic review and meta-analysis of evidence: UNICEF-PHFI series on newborn and child health, India. Indian Pediatr. 2011;48:537-46. Medline:21813923 doi:10.1007/s13312-011-0096-8

41 Kearns AD, Caglia J, ten Hoope-Bender P, Langer A. Antenatal and postnatal care: a review of innovative models for improving availability, accessibility, acceptability and quality of services in low-resource settings. BJOG. 2016;123:540-8. Medline:26694075 doi:10.1111/1471-0528.13818

42 Sebert Kuhlmann AK, Altman L, Galavotti C. The importance of community mobilization in interventions to improve sexual, reproductive, and maternal health outcomes: A review of the evidence. Health Care Women Int. 2016;37:1028-66. Medline:26785861 doi:10.1080/07399332.2016.1141911

43 Mangham-Jefferies L, Pitt C, Cousens S, Mills A, Schellenberg J. Cost-effectiveness of innovations to improve the utilization and provision of maternal and newborn health care in low-income and lower-middle-income countries: a systematic review. BMC Pregnancy Childbirth. 2014;14:243. Medline:25052536

44 Marston C, Renedo A, McGowan CR, Portela A. Effects of community participation on improving uptake of skilled care for maternal and newborn health: a systematic review. PLoS One. 2013;8:e55012. Medline:23390509 doi:10.1371/journal. pone.0055012

45 Mbuagbaw L, Medley N, Darzi AJ, Richardson M, Habiba Garga K, Ongolo-Zogo P. Health system and community level interventions for improving antenatal care coverage and health outcomes. Cochrane Database Syst Rev. 2015;CD010994. -CD. Medline:26621223 doi:10.1002/14651858.CD010994.pub2

46 Parsekar SS, Pundir P, Bevilacqua V. Reproductive, Maternal, Newborn, Child and Adolescent Health and related Behaviour Change Communication strategies in Bangladesh, Nepal and India: A narrative review. Clin Epidemiol Glob Health. 2020;8:2806. doi:10.1016/j.cegh.2019.08.014

47 Jennings MC, Pradhan S, Schleiff M, Sacks E, Freeman PA, Gupta S, et al. Comprehensive review of the evidence regarding the effectiveness of community-based primary health care in improving maternal, neonatal and child health: 2 . maternal health findings. J Glob Health. 2017;7:010902. Medline:28685040 doi:10.7189/jogh.07.010902

48 Perry HB, Sacks E, Schleiff M, Kumapley R, Gupta S, Rassekh BM, et al. Comprehensive review of the evidence regarding the effectiveness of community-based primary health care in improving maternal, neonatal and child health: 6. strategies used by effective projects. J Glob Health. 2017;7:010906. Medline:28685044 doi:10.7189/jogh.07.010906

49 Sarkar A, Chandra-Mouli V, Jain K, Behera J, Mishra SK, Mehra S. Community based reproductive health interventions for young married couples in resource-constrained settings: a systematic review. BMC Public Health. 2015;15:1037. Medline:26452750 doi:10.1186/s12889-015-2352-7

50 Schiffman J, Darmstadt GL, Agarwal S, Baqui AH. Community-Based Intervention Packages for Improving Perinatal Health in Developing Countries: A Review of the Evidence. Semin Perinatol. 2010;34:462-76. Medline:21094420 doi:10.1053/j.semperi.2010.09.008

51 Sharma BB, Jones L, Loxton DJ, Booth D, Smith R. Systematic review of community participation interventions to improve maternal health outcomes in rural South Asia. BMC Pregnancy Childbirth. 2018;18:327. N.PAG-N.PAG. Medline:30097022 doi:10.1186/s12884-018-1964-1

52 Takah NF, Malisheni M, Aminde L. Male Partner Involvement in the Utilization of Hospital Delivery Services by Pregnant Women Living with HIV in Sub Saharan Africa: A Systematic Review and Meta-analysis. Matern Child Health J. 2019;23:71121. Medline:30600506 doi:10.1007/s10995-018-2676-x

53 Wekesah FM, Mbada CE, Muula AS, Kabiru CW, Muthuri SK, Izugbara CO. Effective non-drug interventions for improving outcomes and quality of maternal health care in sub-Saharan Africa: A systematic review. Syst Rev. 2016;5:137. Medline:27526773 doi:10.1186/s13643-016-0305-6

54 Yuan B, Målqvist M, Trygg N, Qian X, Ng N, Thomsen S. What interventions are effective on reducing inequalities in maternal and child health in low- and middle-income settings? A systematic review. BMC Public Health. 2014;14:634. Medline:24952656 doi:10.1186/1471-2458-14-634

55 Singh A, Vellakkal S. Impact of public health programs on maternal and child health services and health outcomes in India: A systematic review. Soc Sci Med. 2021;274:113795. Medline:33667744 doi:10.1016/j.socscimed.2021.113795

56 Perry HB, Rassekh BM, Gupta S, Wilhelm J, Freeman PA. Comprehensive review of the evidence regarding the effectiveness of community-based primary health care in improving maternal, neonatal and child health: 1. rationale, methods and database description. J Glob Health. 2017;7:010901. Medline:28685039 doi:10.7189/jogh.07.010901

57 Ganju S, Khanna R, Taparia M, Hardikar N. Promoting accountability for maternal health through report card. COPASAH Communique. 2014;8:3-5. 
$58 \mathrm{Wu}$ Z, Viisainen K, Wang Y, Hemminki E. Evaluation of a community-based randomized controlled prenatal care trial in rural China. BMC Health Serv Res. 2011;11:92. Medline:21542939 doi:10.1186/1472-6963-11-92

59 Carlo WA, Goudar SS, Jehan I, Chomba E, Tshefu A, Garces A, et al. Newborn-care training and perinatal mortality in developing countries. N Engl J Med. 2010;362:614-23. Medline:20164485 doi:10.1056/NEJMsa0806033

60 World Health Organization. Information, Education and Communication: lessons from the past; perspectives for the future. Geneva: WHO; 2001.

61 Sood S, Chandra U, Mishra P, Neupane S. Measuring the effects of behavior change interventions in Nepal with population-based survey results. Baltimore MD: Jhpiego; 2004.

62 Gonzales F, Arteaga E, Howard-Grabman L, editors. Scaling up the WARMI project: lessons learned. Presented papers: high impact PVO child survival programs; 1999.

63 Aziz A, Shams M, Khan KS. Participatory action research as the approach for women's empowerment. Action Res. 2011;9:30323. doi:10.1177/1476750310396952

64 Smith SL, Shiffman J, Kazembe A. Generating political priority for newborn survival in three low-income countries. Glob Public Health. 2014;9:538-54. Medline:24766101 doi:10.1080/17441692.2014.904918

65 Kwast BE. Building a community-based maternity program. Int J Gynaecol Obstet. 1995;48:S67-82. Medline:7672176 doi:10.1016/0020-7292(95)02321-3

66 Gilmore B, McAuliffe E, Larkan F, Conteh M, Dunne N, Gaudrault M, et al. How do community health committees contribute to capacity building for maternal and child health? A realist evaluation protocol. BMJ Open. 2016;6:e011885. Medline:27807082 doi:10.1136/bmjopen-2016-011885

67 Mason L, Dellicour S, Ter Kuile F, Ouma P, Phillips-Howard P, Were F, et al. Barriers and facilitators to antenatal and delivery care in western Kenya: a qualitative study. BMC Pregnancy Childbirth. 2015;15:26. Medline:25886593 doi:10.1186/s12884015-0453-z

68 Milkowska-Shibata MA, Aye TT, Yi SM, Oo KT, Khaing K, Than M, et al. Understanding Barriers and Facilitators of Maternal Health Care Utilization in Central Myanmar. Int J Environ Res Public Health. 2020;17:1464. Medline:32106467 doi:10.3390/ ijerph17051464

69 Munguambe K, Boene H, Vidler M, Bique C, Sawchuck D, Firoz T, et al. Barriers and facilitators to health care seeking behaviours in pregnancy in rural communities of southern Mozambique. Reprod Health. 2016;13:31. Medline:27356968 doi:10.1186/ s12978-016-0141-0

70 Calvello EJ, Skog AP, Tenner AG, Wallis LA. Applying the lessons of maternal mortality reduction to global emergency health. Bull World Health Organ. 2015;93:417-23. Medline:26240463 doi:10.2471/BLT.14.146571

71 Chakupewa J, Stephen OM. Efficacy of Community Factors in the Implementation of Community-Based Interventions to Improve Antenatal Care: Lessons from IMCHA Programme, Tanzania [Under Review]. Reprod Health. 2021.

72 Kc NP, Kc A, Sharma N, Malla H, Thapa N, Aryal K, et al. Community participation and mobilization in community-based maternal, newborn and child health programmes in Nepal. J Nepal Health Res Counc. 2011;9:101-6. Medline:22929838

73 Martin SL, McCann JK, Gascoigne E, Allotey D, Fundira D, Dickin KL. Engaging family members in maternal, infant and young child nutrition activities in low- and middle-income countries: A systematic scoping review. Matern Child Nutr. 2021;17 Suppl 1:e13158. Medline:34241961 doi:10.1111/mcn.13158

74 Nishimwe C, Mchunu GG, Mukamusoni D. Community- based maternal and newborn interventions in Africa: Systematic review. J Clin Nurs. 2021;30:2514-39. Medline:33656214 doi:10.1111/jocn.15737

75 Braithwaite J, Churruca K, Long JC, Ellis LA, Herkes J. When complexity science meets implementation science: a theoretical and empirical analysis of systems change. BMC Med. 2018;16:63. Medline:29706132 doi:10.1186/s12916-018-1057-z

76 Kroelinger CD, Rankin KM, Chambers DA, Diez Roux AV, Hughes K, Grigorescu V. Using the Principles of Complex Systems Thinking and Implementation Science to Enhance Maternal and Child Health Program Planning and Delivery. Matern Child Health J. 2014;18:1560-4. Medline:25108501 doi:10.1007/s10995-014-1586-9

77 Rabin BA, Brownson RC, Haire-Joshu D, Kreuter MW, Weaver NL. A glossary for dissemination and implementation research in health. J Public Health Manag Pract. 2008;14:117-23. Medline:18287916 doi:10.1097/01.PHH.0000311888.06252.bb

78 Marchal B, Kegels G, Van Belle S. Theory and realist methods. Doing Realist Research 1st ed Los Angeles: SAGE Publications; 2018.

79 Diez Roux AV. Complex systems thinking and current impasses in health disparities research. Am J Public Health. 2011;101:162734. Medline:21778505 doi:10.2105/AJPH.2011.300149

80 Rosato M, Laverack G, Grabman LH, Tripathy P, Nair N, Mwansambo C, et al. Community participation: lessons for maternal, newborn, and child health. Lancet. 2008;372:962-71. Medline:18790319 doi:10.1016/S0140-6736(08)61406-3

81 Richardson EZ, Bandewar SV, Boulanger RF, Mehta R, Lin T, Vincent R, et al. Addressing diversity and complexity in the community engagement literature: The rationale for a realist review. Wellcome Open Res. 2021;5:1. Medline:34632082 doi:10.12688/ wellcomeopenres. 15525.1

82 Dada S, McKay G, Mateus A, Lees S. Lessons learned from engaging communities for Ebola vaccine trials in Sierra Leone: reciprocity, relatability, relationships and respect (the four Rs). BMC Public Health. 2019;19:1665. Medline:31829223 doi:10.1186/s12889-019-7978-4

83 Tindana PO, Singh JA, Tracy CS, Upshur REG, Daar AS, Singer PA, et al. Grand challenges in global health: community engagement in research in developing countries. PLoS Med. 2007;4:e273-e. Medline:17850178 doi:10.1371/journal.pmed.0040273

84 Kågesten AE, Tunçalp Ö, Portela A, Ali M, Tran N, Gülmezoglu AM. Programme Reporting Standards (PRS) for improving the reporting of sexual, reproductive, maternal, newborn, child and adolescent health programmes. BMC Med Res Methodol. 2017;17:117. Medline:28774287 doi:10.1186/s12874-017-0384-7 